\title{
PRODUCTION OF INDIVIDUALISED MULTI-MATERIAL COMPONENTS USING A ROBOT-BASED PROCESS CHAIN
}

\author{
M. Albergt ${ }^{1 *}$, M. David ${ }^{1}$, M. Dross ${ }^{1}$, A.-K. Reichler ${ }^{1}$, H.-W. Hoffmeister ${ }^{1}$, K. Droeder ${ }^{1}$ \\ ${ }^{1}$ TU Braunschweig, Institut fuer Werkzeugmaschinen und Fertigungstechnik, Braunschweig, Deutschland \\ *Corresponding author; e-mail: m.albergt@tu-braunschweig.de
}

\begin{abstract}
The production of individual work pieces in small to medium batch sizes requires an adaptation of the manufacturing strategy. Particularly, the manufacturing of multi-material components out of metal and plastic is characterized by high production costs as well as high production times. To resolve this challenge, a new, modular process chain for the production of these structures in a single manufacturing cell was developed. In this cell, a robot manufactures multi-material components with multiple endeffectors in several successive process steps. In the first step, interlocking structures are manufactured on a metal part by a surface structuring tool. Afterwards, an extruder is used to add a thermoplastic onto the structured metal part. Due to mechanical interlocking effects, the applied thermoplastic shows improved adhesion behavior. A study was conducted to analyze the achievable joint strength of the additive material application onto the structured metal samples. Investigations to determine the achievable manufacturing quality of a robot guided milling process for multi-material parts have been carried out. A recently developed suction hood is used to capture the metal and plastic chips. In this paper, the results regarding the efficiency of the individual end-effectors, including the extraction hood, are presented and it is demonstrated how they interact within the robot-based process chain.
\end{abstract}

\section{Keywords:}

flexible manufacturing system; robot; multi-material manufacturing

\section{INTRODUCTION}

Customized components are becoming increasingly important in everyday production in numerous industries. This leads to a growing number of variants with a simultaneous variation in the batch sizes to be produced. At the same time, the established, unit-count production techniques are losing their profitability due to high investment in capital for product-specific tools. The demand for cost-efficient and flexible production processes is particularly driven by the rapidly growing market of components in multi-material design [Witten 2018]. The resulting components are mainly made from the combination of metal, plastic and fibers, as these are characterized by a high potential for lightweight construction applications as well as for functional integration. Applications for such multi-material components include medical technology, the automotive industry and sports equipment [Maidin 2015]. However, these multi-material components are currently manufactured in complex manual processes like hand laminating (small batch size) or in mold-based processes (large batch sizes). These processes are either characterized by high production times and low degree of automation or high product-specific costs. To resolve this challenge, a new, modular process chain for the production of these structures in a single manufacturing cell was developed. In this cell, a robot manufactures multi-material components with multiple end-effectors in several successive process steps [Reichler 19].

In this process chain three consecutive manufacturing steps are carried out. In the first step, interlocking structures are manufactured on a metal part by a new developed surface structuring tool. These interlocking structures are used to improve the adhesive strength of plastic that is printed on the metal surface in the second process step. An extruder is used for this process step, to apply a thermoplastic on the structured metal part. In the last process step, a robot-guided milling process is used to achieve the required work piece geometry and smoothen the surface. Thereby, a suction hood captures the metal and plastic chips to ensure further manufacturing steps.

In this paper, it is experimental demonstrated how the different robot end-effectors interact within the developed process chain. In order to determine the optimal setting parameters for the structuring process, the preload force as well as the angle of attack of the structuring tool were varied during the experiments. In this way, interlocking structures with different depth and height were applied in aluminum as well as steel. These were then printed on with plastic, whereby the angle of the extruder, the printing direction and process temperature were systematically varied. Investigations were carried out to determine the achievable 
bonding strength between the interlocking structures and the applied plastic. For the robot-guided machining, the low stiffness of the robot, presents a significant challenge for the manufacturing of multi-material components. Therefore, the surface roughness that can be achieved during the milling process was investigated. Further, the chips produced in the process were captured with the newdeveloped extraction hood and the degree of chip detection was determined.

\section{CHALLENGES IN ROBOT-GUIDED MANUFACTURING PROCESSES FOR METAL PLASTIC COMPONENTS}

As presented in [Reichler 2019] and [Dross 2021] the challenges in a cost efficient production of metal-plastic components are versatile. Recent research work in the field of metal-plastic component manufacturing focuses in particular on technologies for increasing composite strength. In this context, the bond between metal and plastic is achieved on the one hand by adhesion, but also by mechanical interlocking structures [Gradinger 2010, Rauch 2009, Arbesman 2000]. The interlocking structures manufactured in the course of this research are based on so-called "HyTensile" structures [Brand 2016]. Here, mechanical interlocking enables a form-fit connection between the structured metal component and injection molded thermoplastics, with the plastic component filling the cavities of the structured surface. Although improving the bonding between metal and thermoplastics, these technique was only verified on plane surfaces in a static way. In [Dross 2021] a robot guided, fully automated structuring tool for a more versatile and dynamic process was developed. In this research the use of the tool is demonstrated and experiments are carried out to characterize the structures produced by the tool. For the application of the thermoplastics an extruder based fused deposition modeling (FDM) process is used. Currently no investigations were carried out to determine, if a FDMbased extrusion process is feasible for application of thermoplastics onto the structured surface. Different printing angles and orientations of the extruder have to be investigated, as this may influence the filling of the structures.

Currently, robots carry out only about $5 \%$ of manufacturing processes. They are primarily used for component handling or positioning tasks [Klimchik 2016]. Due to their high flexibility and low investment costs, they are increasingly being used for machining and 3D printing as well. However, the lower stiffness of robots compared to machining centres is critical [Pan 2006, Chen 2018]. This can lead to an unstable process, which strongly depends on the adjustment of the robot axes [Chen 2018a]. This is a significant challenge, especially when machining multimaterial components with robots. The different material properties of thermoplastic or thermoset plastics and metals result in separate process windows for machining. This often leads to an unstable process, which results in poor surface quality [Pan 2006]. Therefore, current research is mainly aimed at analysing the machining process to optimize the accuracy of the robot [Mejri 2016, Lejun 2017].

\section{EXPERMINETAL INVESTIGATIONS}

Within the experimental investigations, the different robot end-effectors as well as process parameters for the implementation of the integrated process chain for multimaterial components are investigated.

\subsection{Surface structuring process}

The experimental investigations aimed to determine the geometrical changes of the interlocking structures as a function of the spring pre-load of FauST (Fully automated Structuring Tool, Figure 1) [Dross2021].

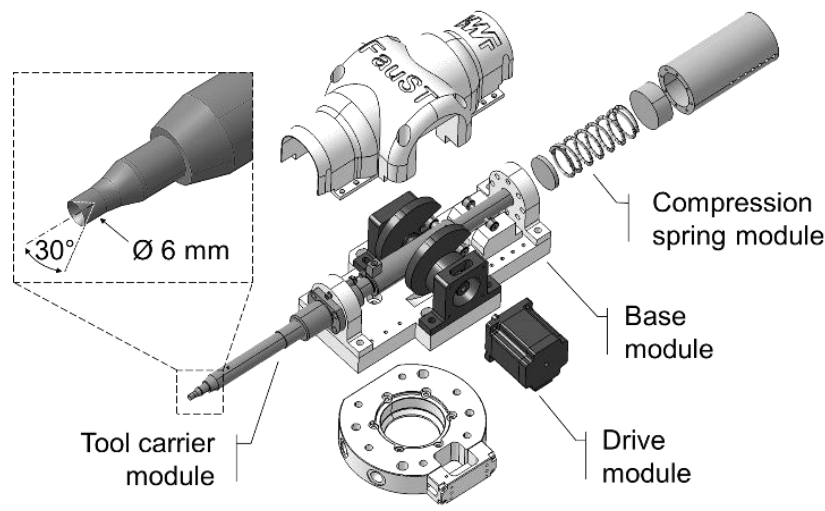

Figure 1: FauST - Fully automated Structuring Tool

This robot end-effector is based on four modules. A base module, a compression spring module, a drive module and a tool carrier module. The base module can be considered as the platform and housing of the end effector. All other modules are attached to it. The drive module consists of a stepping motor, a shaft and two eccentric discs. As a result of the rotation of the eccentric disks, the tool carrier is moved translationally and pre-loads the compression spring. The compression spring module serves as an energy store and accelerates the tool carrier as soon as the eccentric disks rotate beyond the tipping point. The compression spring module can additionally adjust the spring pre-load by using a screw washer, so that different punching forces are available. Afterwards, the tool carrier is accelerated immediately and performs a punching impact motion on the work piece. Due to the tool geometry, an interlocking structure is formed. As part of the project and based on [Brand 2016], the angle of the tool cutting edge was $30^{\circ}$ at any time of the tests.

The spring pre-load force thereby works as a passive expression of the punching force. The tests were carried out for aluminum (3.3535) and steel (1.0330) where nine structures $(3 \times 3)$ were introduced per specimen. The yield strengths of the materials differ by about $80 \mathrm{MPa}$ for aluminum and $230 \mathrm{MPa}$ for steel. Depending on the material, eight specimens were tested. The experimental process parameters are listed in Table 1.

Table 1: Process parameters for the structuring tests

\begin{tabular}{|c|c|}
\hline Description & Value \\
\hline Specimen $L \times B \times H$ & $100 \times 30 \times 3 \mathrm{~mm}$ \\
\hline Spring ratio $k$ & $5,541 \mathrm{~N} / \mathrm{mm}$ \\
\hline Max. Spring pre-load $F_{n}$ & $336,8 \pm 21,1 \mathrm{~N}$ \\
\hline Material & \begin{tabular}{|l|l|}
1.0330 & 3.3535 \\
\end{tabular} \\
\hline
\end{tabular}

For the experimental investigations, a KUKA KR 60-HA-C was used. In order to monitor the upcoming loads on the robot interface during the tests, they were measured with a Force-Torque sensor (Figure 2). The loads applied by the process reached a maximum of $F_{z}=273 \mathrm{~N}$ and a torque of $M_{y}=50 \mathrm{Nm}$. These are far below the maximum torques $(200 \mathrm{Nm})$ of the robots $6^{\text {th }}$ axis. Cross-sections were measured by microscope for the geometrical characterization of the interlocking structures. 

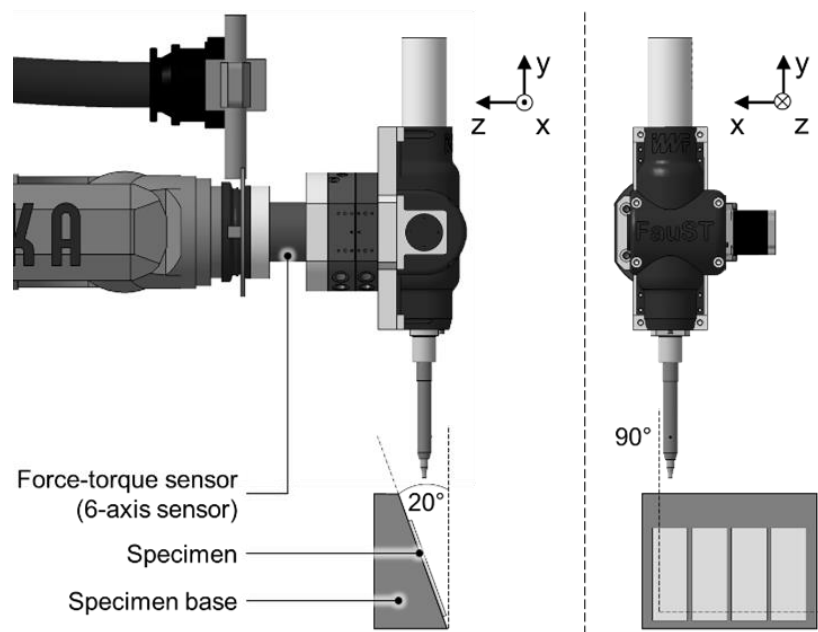

Figure 2: Experimental setup for the structuring tests

Below the results of the interlocking structure characterizations are presented. Thereby, linear correlations with the punching force can be observed for the structure heights, widths and depths, the penetration depths as well as the aspect ratios and projected areas. A comparison of the results shows at first, that in steel the structures reach less structure width with similar structure height to aluminum (Figure 3 ). This is due to the fact no significant differences in the penetration depths SET for the two materials were found in the investigated force range, though lower structure depths $\mathrm{S}_{\mathrm{T}}$ for the material with higher strength were observed (Figure 4). The results show the influence of the robot flexibility in changes of the structuring angle of attack for higher strength materials.

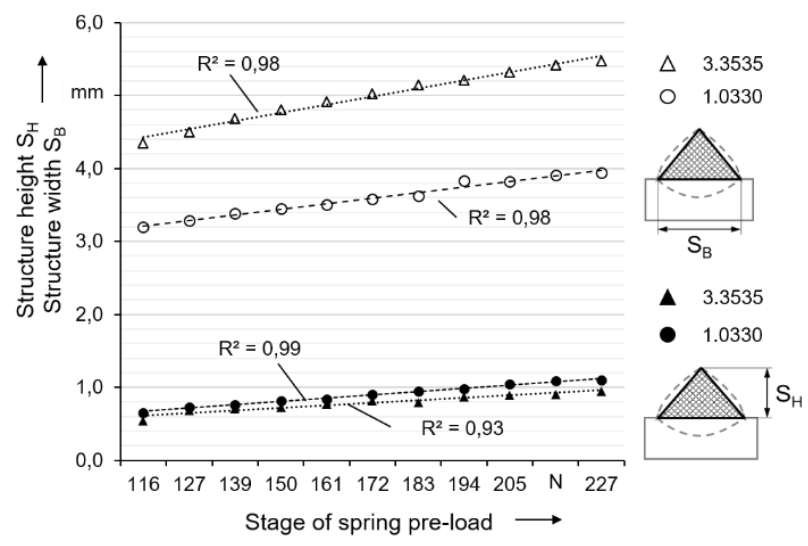

Figure 3: Structural heights $S_{H}$ and structural widths $S_{B}$ for aluminum and steel at different stages of spring pre-load

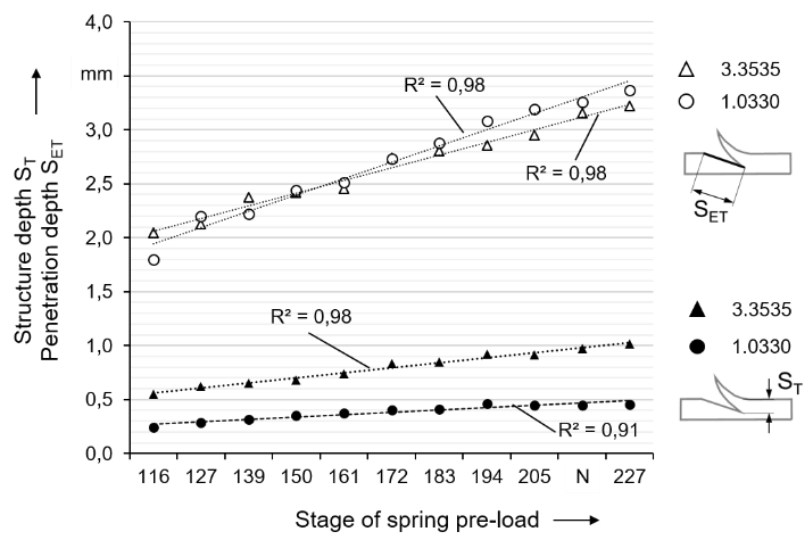

Figure 4: Structural depths $S_{T}$ and penetration depths $S_{E T}$ for aluminum and steel at different stages of spring pre-load

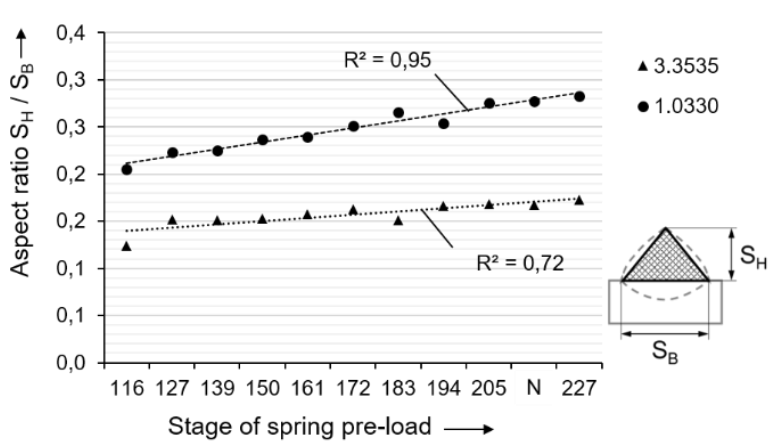

Figure 5: Aspect ratios $\mathrm{S}_{\mathrm{H}} / \mathrm{S}_{\mathrm{B}}$ for aluminum and steel at different stages of spring pre-load

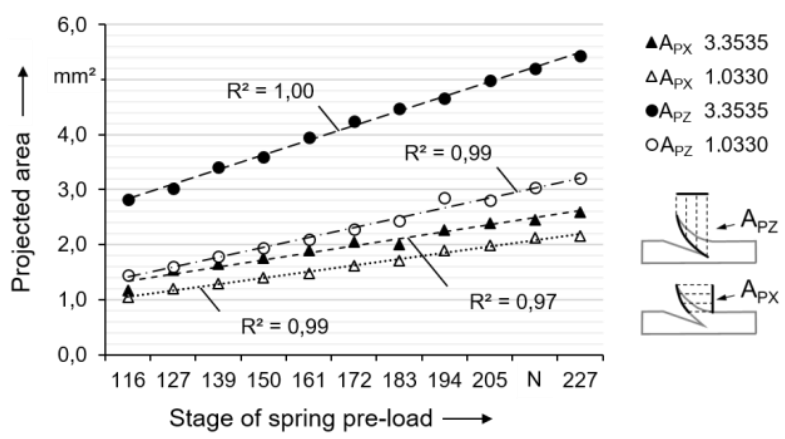

Figure 6: Projected areas $A_{P x}$ and $A_{P Z}$ for aluminum and steel at different stages of spring pre-load

Because of the similar penetration depths $\mathrm{S}_{\mathrm{ET}}$ and different structure depths $S_{T}$, larger aspect ratios with a reduced projected area Apz result for the higher strength material (Figure 5 and Figure 6). The projected area Apx, which is important for the shear tensile strength, only shows minor differences as a result of the same penetration depths. Therefore, similar shear tensile strengths could be assumed for both materials.

Figure 7 shows the geometric evolution of the generated interlocking structures as a function of the spring pre-load. The cross-section images indicate a much more fragile structure for the higher-strength material (1.0330). This is particularly explained by the lower structure depth Sт. Here, the angle of the tool cutting edge $\left(30^{\circ}\right)$ is significantly responsible for the formation of the structure.

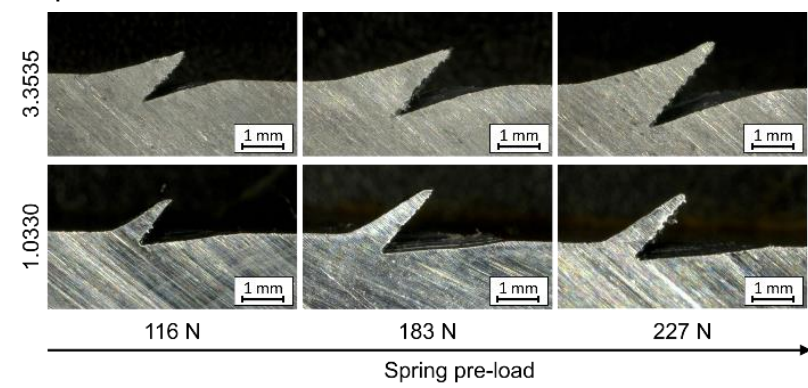

Figure 7: Evolution report of the geometric characteristics of FauST-generated interlocking structures with increased spring pre-load for aluminum and steel

After the characterization of the generated interlocking structures was completed, the achievable shear tensile strengths in the metal-plastic composite were investigated. This was done by applying plastic onto the structured specimens using a robot-based extruder system. The specimens were printed with plastic in a direction crosswise to the tensile direction. For the plastic application process Acrylonitrile-butadiene-styrene copolymers (ABS) was 
used. Depending on the supplier, tensile strengths range from $37 \mathrm{MPa}$ to $44 \mathrm{MPa}$. The glass transition temperature of $A B S$ is in the range of $110^{\circ} \mathrm{C}$ to $125^{\circ} \mathrm{C}$. The melting temperature is between $210^{\circ} \mathrm{C}$ and $240^{\circ} \mathrm{C}$. According to the supplier's specifications, $A B S$ is processed in the range of $240^{\circ} \mathrm{C}$ to $250^{\circ} \mathrm{C}$. To ensure the highest possible bond quality of the extruded plastic to the interlocking structures, a heated mold was used to produce the shear tensile specimens. The heated nozzle was set to a temperature of $150^{\circ} \mathrm{C}$, avoiding premature recrystallization of the polymer In a subsequent abrasive process, the plastic joining partners were manually reworked after the plastic application process in order to reduce the amount of notches in the surface of the printed specimen and specify the dimensions and the overlap length in accordance with ISO 291:2008. The shear tensile tests were carried out on a Zwick/Roell universal testing machine using the listed test specification. With the interlocking structures, high shear tensile strengths are achieved compared to a bond with adhesion promoter or an adhesive (from $12 \mathrm{MPa}$ to $25 \mathrm{MPa}$ in lap shear test [3M 2021]).

Figure 8 shows the shear tensile forces obtained for a single structure as a function of the spring pre-load force for the materials investigated. Similar to the previous results, there is a linear correlation between the resulting shear tensile loads and the applied spring pre-load. The peak shear tensile force of a single structure was measured at $246 \mathrm{~N}$ for aluminum. The failure behavior of the tested specimens was the same for all specimens and can be described as unbuttoning of the interlocking structures from the plastic, resulting in a failure of the ABS. In comparison with [Brand 16] the resulting loads are smaller, due to a different thermoplastic used in these experiments. With PA6GF30 having a higher ultimate strength than ABS (up to $120 \mathrm{MPa}$ for PA6GF30) one structure can withstand forces up to $632 \mathrm{~N}$ at a projected area Apx of $3 \mathrm{~mm}^{2}$.

While the unbuttoning is occurring in single-lap tests due to the bending moment, the bending of the structures in stee is caused by their low geometrical moment of inertia.

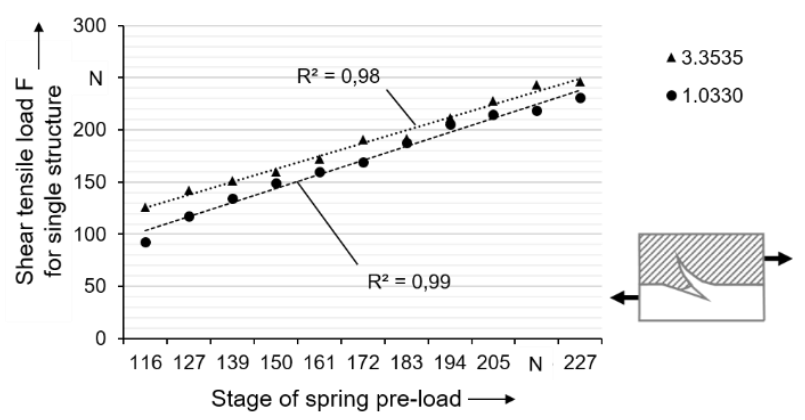

Figure 8: Shear tensile load $F$ for aluminum and steel at different stages of spring pre-load

To determine the stresses in shear endured by a single structure per spring pre-load, the values of the projected area Apx already measured were used and related to the shear tensile forces. Compared to the previous results, there is no clear linear correlation between the shear stress and the spring pre-load (Figure 9). A potential reason could be the premature unbuttoning failure of the specimens. However, it can be seen that similarly high shear tensile stresses can be achieved regardless of the structura characteristics. Furthermore, the unbuttoning failure shows, that the metal structure can withstand greater forces then so far tested. Future tests will conduct double-lap shear tensile tests to minimize bending and lever-effects on the hybrid structure.

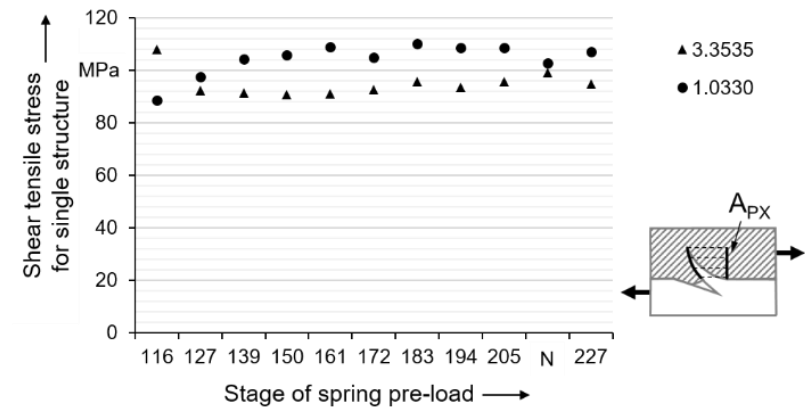

Figure 9: Shear tensile stresses for aluminum and steel at different stages of spring pre-load

\subsection{Improved bonding strength between metal and plastic}

As presented in the previous chapter, the use of interlocking structures has a great potential for creating a strong connection between metal and plastic. Besides many different process parameters like processing temperature, robot speed or the extrusion rate, the angle between the orientation of the structures and the plastic application direction has a great influence on the maximum bond strength. For creating the metal-plastic part, aluminum (3.3535) and ABS are used. The metal structures used in the early experiments were created by hand. The results thus differ from those achieved with FauST in terms of maximum strength and appearance. The used process parameters are presented in Table 2.

Table 2: Process parameters for the plastic application

\begin{tabular}{|l|l|}
\hline Parameter & Value \\
\hline Heating bed temperature & $150^{\circ} \mathrm{C}$ \\
\hline Robot speed/Application speed & $10 \mathrm{~mm} / \mathrm{s}$ \\
\hline Extrusion rate & $63.5 \mathrm{~mm} / \mathrm{s}$ \\
\hline Layer height & $2 \mathrm{~mm}$ \\
\hline Bead width & $5 \mathrm{~mm}$ \\
\hline Nozzle distance from application surface & $2 \mathrm{~mm}$ \\
\hline Structure height $\mathrm{S}_{\mathrm{H}}$ & $1.4 \mathrm{~mm}$ \\
\hline Number of structures per specimen & 8 \\
\hline
\end{tabular}

The experiments include four different orientations for the plastic application process (Figure 10) and three different processing temperatures. At an angle of 0 degrees, the Extruder moves in the direction of the structures, while at 45 degrees it moves diagonal, at 90 degrees perpendicular and at 180 degrees in the opposite direction of the structures resulting in a different amount of plastic in the cavity.

On the one hand, a higher process temperature leads to a better filling of the cavity due to a lower plastic viscosity. On the other hand, also the application direction of plastic has an influence on the filling (Figure 10). A process direction of $0^{\circ}$ to $90^{\circ}$ leads to good results regarding the infill of the cavity structures. The extruded material is pushed into the cavity. At $90^{\circ}$ the maximum infill is achieved. Process directions between $90^{\circ}$ and $180^{\circ}$ decrease the infill of the cavity, since the plastic is placed over the top of the structure's tip. A lower or even no interlocking effect between metal and plastic is caused. 


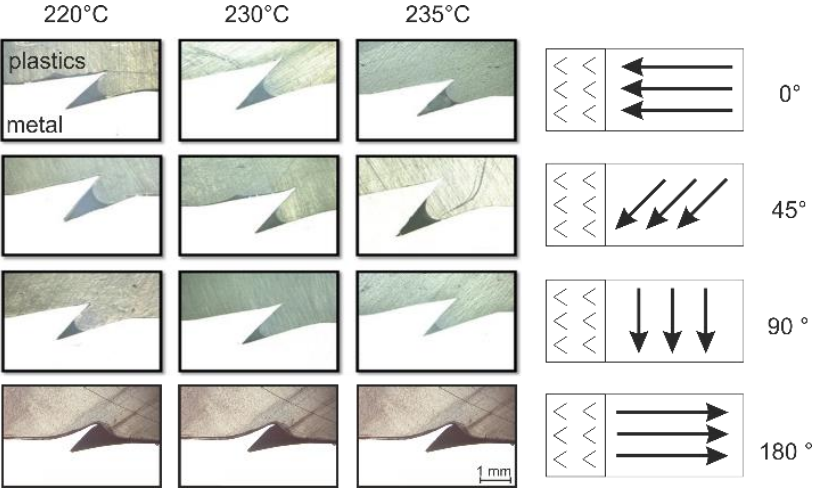

Figure 10: Cross-section of specimen (hooks) printed on by different process directions (arrows) and printing temperatures

Depending on the filling of the cavities different tensile strengths can be achieved, as shown in Figure 11. A higher infill leads to a better bonding strength. In detail, the tensile strengths vary in a range of $50.1 \pm 2.3 \mathrm{MPa}\left(0^{\circ}\right)$, $58.4 \pm 5.1 \mathrm{MPa}\left(45^{\circ}\right)$ and $57.4 \pm 3.7 \mathrm{MPa}\left(90^{\circ}\right)$. In the end all of the process directions less than 90 degrees are applicable for creating a reliable connection between metal and plastic. This results in a high degree of freedom regarding the path-planning of the process in dependence of part related restrictions like reachability of tools (Faust and Extruder) or complexity of the part surface.

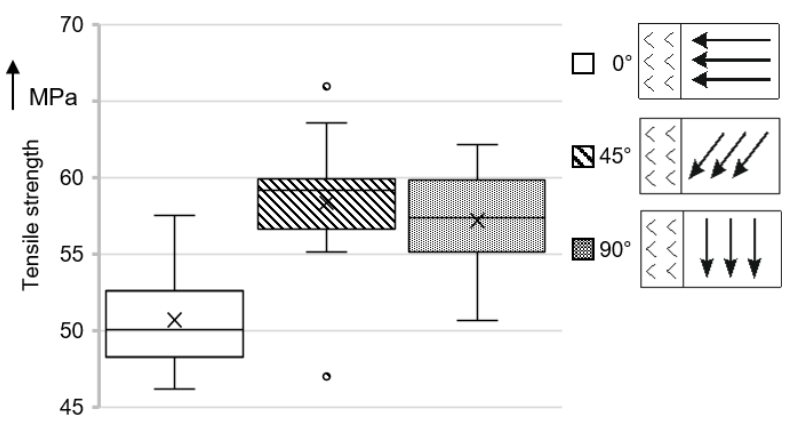

Figure 11: Tensile strength for different process directions at $230^{\circ} \mathrm{C}$ processing temperature (10 samples)

Further tests were carried out regarding the inclination of the extruder to the surface in order to improve the infill ratio of the cavities. The process results of the tilted extruder on a macro scale (whole part-look and feel) are similar to the results of the non-tilted extruder. However, at a micro scale (micrograph of structures) a difference of the infill ratio can be observed (Figure 12).

In the micrograph of the non-tilted structure (Figure 12, right) a better filling of the cavity is visible. Whereas in contrast the structure processed with a tilted extruder displays a lower infill. Due to the tilted extruder the plastic does not flow directly into the cavity, but slightly on top of it. This covers the cavity before more material can infiltrate. With a non-tilted extruder, the plastic flow is evenly distributed in the cavity and can thus fill the cavity better and more evenly.

The connection applied by the tilted extruder shows lower tensile-strength than the one applied by the non-tilted extruder. The average bond strength $(37.9 \pm 9.6 \mathrm{MPa})$ achieved by a tilted extruder is low and fluctuates compared to the one with a non-tilted extruder.

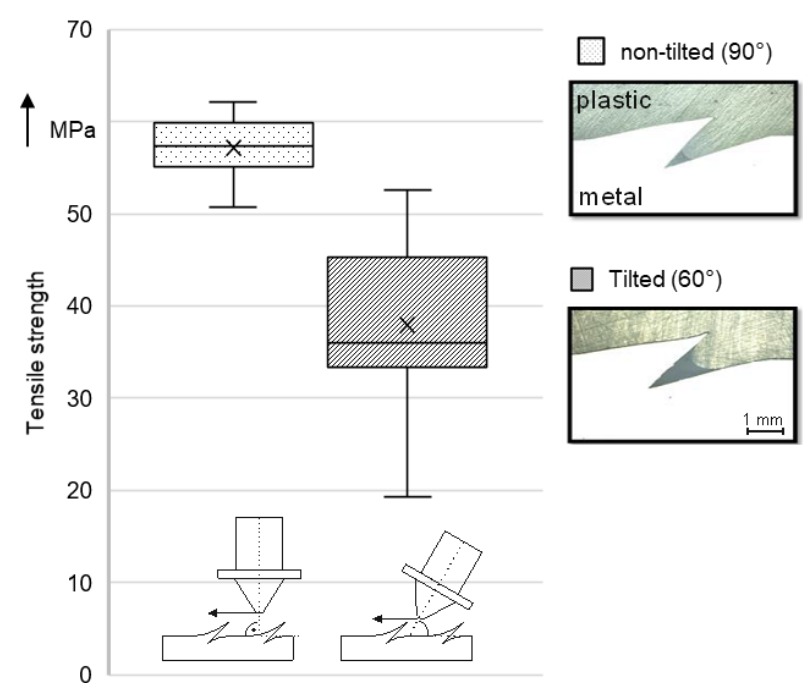

Figure 12: Influence on the filling of the structures between non-tilted $\left(90^{\circ}\right)$ and tilted $\left(60^{\circ}\right)$ extrusion and on the tensilestrength of a single structure

The presented results on different process directions of the extruder and the way the structures are approached can be used to improve the bond strength. The best result was realized for an extruder that moved perpendicular to the surface. It is recommended to consider the path-planning of the structuring process while planning the paths for the additive process. As long as the plastic application path and the structuring path have an orientation of $0^{\circ}$ to $90^{\circ}$ towards each other, the cavities of the structure are reliably filled and reach tensile strengths between $48 \mathrm{MPa}$ and $60 \mathrm{MPa}$.

\subsection{Robot-guided milling process}

In the last step of the process chain, a robot-guided milling process is used to rework the applied plastic. This step is necessary to finish the component and to create the required surface quality. In order to determine the achievable manufacturing quality, machining tests were first carried out on the individual components aluminum and ABS. These were bonded with a 2-component acrylic adhesive to form a hybrid material in order to compare the influence of both materials on the manufacturing result. This represents the worst-case scenario, in which not only the plastic is machined but the tool also comes into contact with the metal. This happens when large geometric deviations have occurred due to deviations in the preceding process steps. For the investigations, a KUKA KR300 robot with a machine spindle was used (Figure 13). A $12 \mathrm{~mm}$ solid carbide milling cutter with DLC coating, three cutting edges and a helix angle of $45^{\circ}$ was used for the cutting process.

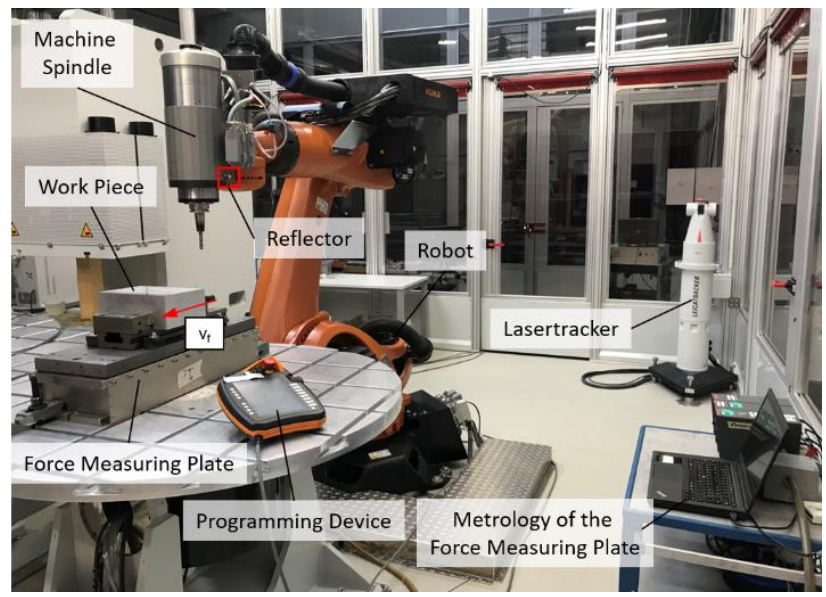

Figure 13: Experimental setup 
During the investigations, the process parameters were varied in terms of cutting speed and feed rate in order to develop optimum setting parameters for the milling process. Starting with a cutting speed of $\mathrm{v}_{\mathrm{c}}=300 \mathrm{~m} / \mathrm{min}$ and a feed rate of $V_{f}=1980 \mathrm{~mm} / \mathrm{min}$ since these parameters led to a good surface quality of approximately $\mathrm{Rz}=2 \mu \mathrm{m}$ in preliminary tests. Subsequently, the cutting parameters were systematically varied. The resulting surface was subsequently measured. The depth of cut was set at $a_{p}=10 \mathrm{~mm}$ in order to obtain a sufficiently large area for measuring the surface quality. The starting value for the cutting width was set to $a_{e}=0.5 \mathrm{~mm}$ and was subsequently increased up to the full cutter diameter (12 mm, full groove). Synchronous milling was used as machining strategy. A Hommel Tester T1000 roughness tester was used to determine the surface quality, with the measuring direction corresponding to the feed direction of the robot.

During machining, a trend was observed up to a cutting speed of $v_{c}=600 \mathrm{~m} / \mathrm{min}$, where a reduction in the average roughness depth occurs with an increasing cutting speed (Figure 14). This occurred in both ABS and aluminum.

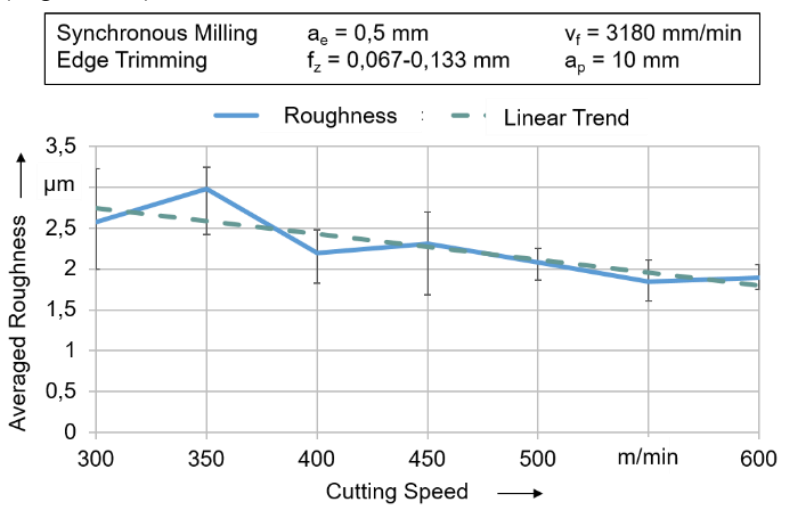

Figure 14: Surface roughness during the milling process

The lowest surface roughness was measured in the plastic at a cutting speed of $v_{c}=550 \mathrm{~m} / \mathrm{min}$. This value was then used as the foundation for varying the feed rate, which was set between $v_{f}=1980 \mathrm{~mm} / \mathrm{min}$ and $v_{f}=6780 \mathrm{~mm} / \mathrm{min}$. The best results were measured at a feed rate of $\mathrm{V}_{\mathrm{f}}=3180 \mathrm{~mm} / \mathrm{min}$ with a surface roughness of $R z=1.85 \mu \mathrm{m}$. The lowest roughness depth in aluminum was $R z=1.87 \mu \mathrm{m}$ and was achieved at a feed rate of $\mathrm{V}_{f}=2580 \mathrm{~mm} / \mathrm{min}$.

With these setting parameters, full grooves were milled. In the aluminum component, strong chatter occurred from a cutting depth of $a_{p}=5 \mathrm{~mm}$. The chatter marks appear in form of heavy scoring and irregularities, both on the bottom of the groove and on the flanks. Further investigations proved that by reducing the feed rate to $V_{f}=1680 \mathrm{~mm} / \mathrm{min}$, the process can be stabilized and chatter prevented. Thus, the investigations could be continued up to a maximum cutting depth of $a_{p}=12 \mathrm{~mm}$.

When the tool enters the plastic, it is displaced from the programmed path orthogonally to the feed direction ( $Y$ direction). At the material transition to aluminum, the cutting force increases significantly, resulting in an offset to the original path in the ABS. This remains in the aluminum during cutting and is not corrected by the robot. At the end of the milling process, the cutting force drops and the robot returns to the programmed path, resulting in a further shape deviation. The evaluation of the position measurement recorded with a Lasertracker shows a lateral displacement of up to $0.15 \mathrm{~mm}$ with the entry of the milling cutter into the plastic. During milling, the tool is displaced from the actual path by up to $0.92 \mathrm{~mm}$, resulting in a total shape deviation of $1.15 \mathrm{~mm}$. After the tool exits the material, the robot returns to the programmed path. The material transition is clearly visible from the position measurements (Figure 15).
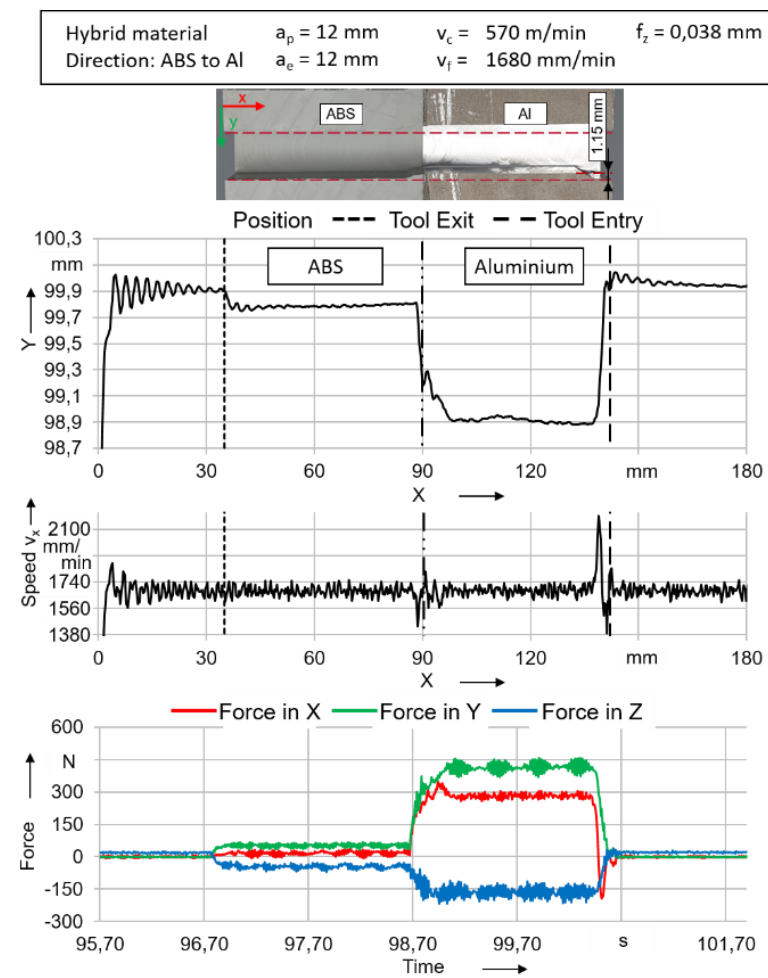

Figure 15: Measuring results for full groove milling

The velocity diagram shows a brief drop at the material transition, followed by a subsequent increase. Here the robot is slowed down by the higher cutting forces in the aluminum and compensates this with an overshoot. When the tool left the work piece, the velocity rises abruptly to $2196 \mathrm{~mm} / \mathrm{min}$. This is compensated immediately by the control of the robot. The force measurement shows a cutting force of $100 \mathrm{~N}$ in the ABS and $592 \mathrm{~N}$ after the material transition to aluminum. During the process, this corresponds to an increase in forces by a factor of six at the material transition, which results in the form deviation of the full groove.

By measuring the cutting forces during machining, the material transition between the plastic and metal can be detected. Despite the deviations, surface roughness's of $\mathrm{Rz}=2.26 \mu \mathrm{m}$ in $\mathrm{ABS}$ and $\mathrm{Rz}=2.03 \mu \mathrm{m}$ in aluminum were achieved in full groove milling. These are only slightly rougher compared to the edge trimming process.

The differences in the process characteristics of the ABS and aluminum materials can clearly be seen in the measurements. The material transition is evident from a position deviation in the $\mathrm{Y}$-direction and the different process forces. This deviation is due to the low stiffness of the robot. Currently, a process control is developed to detect the material transition between metal and plastic using the process forces. This is intended to counteract the deviation of the tool and improve the manufacturing process.

\section{Chip extraction}

The metal and plastic chips arising during machining have to be removed from the working area to prevent an influence on the subsequent processes like the further application of plastic. For this purpose, an extraction hood that is capable of capturing all metal and plastic chips in the direct vicinity of the tool was developed (Figure 16). The 
extraction hood works according to the baffle plate principle, which is used in woodworking machines as well. The chips hit an impact surface and are decelerated abruptly so their kinetic energy is strongly reduced. Therefore, they can easily be extracted. Three electric cylinders allow a movement of the extraction hood by up to $200 \mathrm{~mm}$. Thereby, a simple lifting movement as well as a tilting of the hood by an angle of up to $30^{\circ}$ is possible.

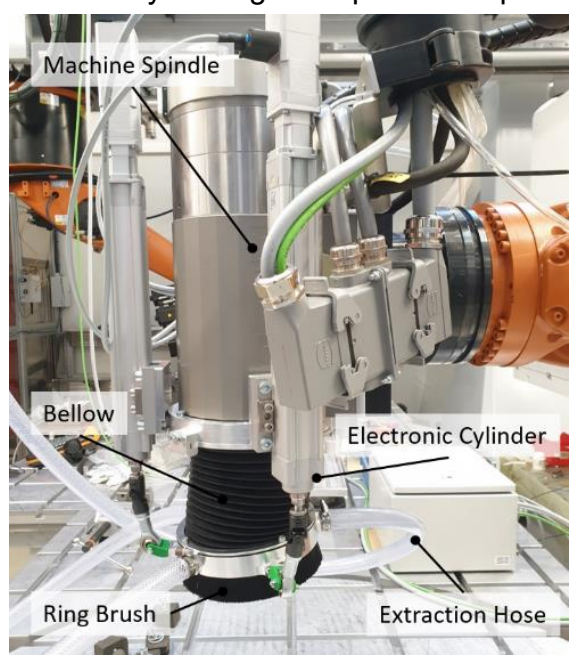

Figure 16: Extraction Hood

The extraction hood is connected to an extraction system that allows an effective volume flow of up to $5000 \mathrm{~m}^{3} / \mathrm{h}$ to be achieved. During the machining tests, the performance of the suction hood was investigated by determining the degree of chip capture during the machining tests. This was done when trimming the work piece edges and for full groove milling as well. For the investigations, the cutting parameters that led to the best surface qualities in the proceeding tests were used. To determine the degree of chip capture, the machined volume as well as the machined mass was calculated from the setting parameters and the density of the individual materials. Subsequently, during the machining tests, all chips that were not captured by the suction hood were collected and weighed using a scale. The weight of the chips was then subtracted from the calculated machined volume and the chip collection efficiency of the extraction hood was determined. In the investigations, the extraction hood was tilted up to $30^{\circ}$ and the height of the aluminum ring was varied as well, in order to determine the optimal position of the hood for machining. Five different positions were set up. The study started with the extraction hood positioned horizontally $\left(0^{\circ}\right)$ at work piece height. Therefore, the milling cutter extends $10 \mathrm{~mm}$ out of the extraction hood. In the second position, the extraction hood was set horizontally $\left(0^{\circ}\right)$ to the projection length of the milling cutter. At last, the hood was tilted by $15^{\circ}$ as well as by $30^{\circ}$ to the milled surface. During the groove milling process, the extraction hood was set to the work piece height only.

Chip capture tends to be higher for ABS compared to aluminum because the resulting chips are lighter due to the lower density of ABS (Figure 17. Most chips were captured when trimming $A B S$ with a tilted extraction hood by an angle of $15^{\circ}$. In this case, the chip capture rate was $97 \%$ on average. With a capturing rate between $90 \%$ at an angle of $30^{\circ}$ and $77 \%$, when the extraction hood is set at the same height as the tool, the extraction hood shows very good results. During the machining of aluminum, a chip capturing rate between $65 \%$ at $15^{\circ}$ inclination and $59 \%$ at $30^{\circ}$ inclination was achieved. When the extraction hood was set to the work piece height, only $30 \%$ of the metal and plastic chips were captured. That is because in this position the extraction hood does not enclose the tool. Therefore, the chips do not hit the aluminum ring properly and are not completely slowed down, which makes the extraction more difficult. When trimming the hybrid material, the best results were achieved with an angle of $15^{\circ}$ (chip collection rate $\sim 73 \%$ ). When the hood is set at tool height, $70 \%$ of the chips were captured which is only slightly different from the $30^{\circ}$ angle at which $67 \%$ of the chips were collected. The lowest degree of chip detection is achieved when the tool is set at the height of the work piece.

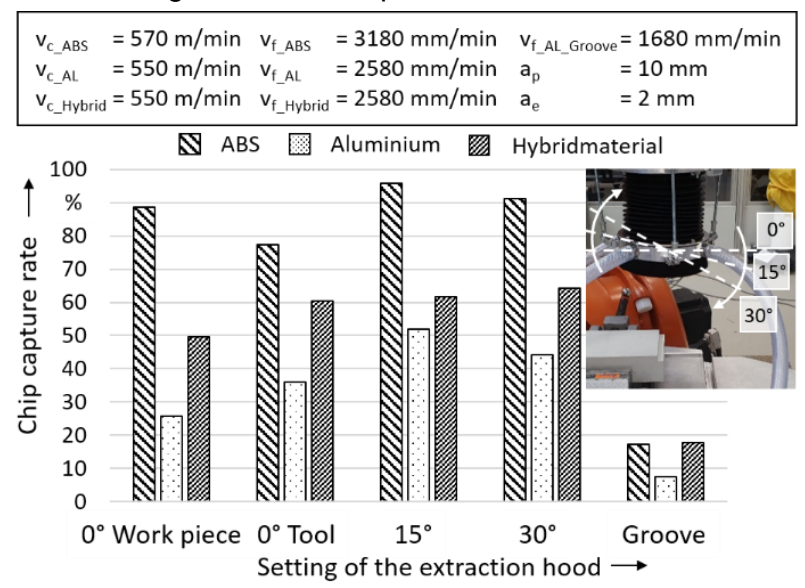

\section{Figure 17: Performance of the extraction hood}

During full groove milling, the chip collection rate is currently significantly lower than the values achieved during edge trimming. On the one hand, this is due to the significantly larger chip cross-section and therefore the higher weight of the chips. These are, on average, heavier by a factor of six. On the other hand, the investigations of the extraction hood's performance have not been completed yet. Thus, at present, the optimum setting position of the extraction hood for the groove milling process has still to be found. Despite the significantly lower chip collection rate in full groove milling, the use of the extraction hood during machining is recommended. The extraction hood captures plastic dust and at least prevents the chips from being distributed in the manufacturing cell in an uncontrolled manner. This means that the metal and plastic chips remain in the immediate vicinity of the cutting point and can be removed much more easily afterwards.

\section{SUMMARY AND OUTLOOK}

In this paper investigations for a flexible robot based process chain for metal-plastic components were shown. Therefore, metal parts were pretreated with the "FauST" structuring tool. This significantly increased the bond strength to the subsequently imprinted plastic.

The plastic application process has to be planned accordingly to the generated interlocking structures on the surface of the metal part. The orientation of the extruder should be set perpendicular to the surface. Furthermore, the structures have to be approached by the extruder in an angle between $0^{\circ}$ and $90^{\circ}$. With paths according to the recommendations, a bond strength of $204.2 \pm 17.8 \mathrm{~N}$ per structure can be achieved for the combination of aluminum and ABS, showing a great potential for an automated production of hybrid parts.

In the milling process with a robot, surface qualities of approximately $\mathrm{Rz}=1.85 \mu \mathrm{m}$ can be achieved. For trimming, the process can be set at a cutting speed of $\mathrm{v}_{\mathrm{c}}=570 \mathrm{~m} / \mathrm{min}$ with a feed rate of $v_{f}=2580 \mathrm{~mm} / \mathrm{min}$ in aluminum and 
$V_{f}=3180 \mathrm{~mm} / \mathrm{min}$ in ABS. Only for full groove milling the feed rate must be reduced to $\mathrm{V} f_{\mathrm{f}}=1680 \mathrm{~mm} / \mathrm{min}$ in order to achieve a stable process.

Based on the obtained results, further research has to focus in characterizing more material combinations. Thereby, fiber-reinforced thermoplastics should be used to determine the potential ultimate strength of the structures for metal plastic combinations. Moreover, the maximum amount of structures per $\mathrm{mm}^{2}$ on the surface of a part should be investigated. As shown in [Brand 16] the positioning and arrangement of the structures on an even surface has an influence on the maximum load-bearing for injection molded parts. Thus, experiments for an FDM-based application of thermoplastics have to be carried out to identify the maximum amount of structures per $\mathrm{mm}^{2}$.

In addition to that, a demonstrator has to be manufactured to show the potential and flexibility of the presented robot based process chain in lab-scale. To simplify the process, a planning tool for the robot parts have to be developed, that, besides the path-planning of the robot, determines the dimensions and orientation of the structures related to the loads acting on the part.

However, the milling results in position deviations on the hybrid material, which must be compensated for reliable process control. For this purpose, a process control will be developed in further work to detect the material transition between metal and plastic. For this, the cutting forces will be used to detect the beginning and the end of the milling process as well as the material transition. It is also possible to calculate the path deflection with the measured milling force. The new developed suction hood is capable of capturing up to $97 \%$ of the occurring metal and plastic chips during edge trimming. Further investigations will be carried out to find the optimal setting position for the full groove milling

\section{ACKNOWLEDGMENTS}

This paper is part of the research project "HyLight3D", which is funded by the Federal Ministry of Education and Research, in the context of "KMU-Innovationsoffensive Produktionsforschung". The entire project consortium is composed of one institute from TU Braunschweig (Institute of Machine Tools and Production Technology) as well as three SME industrial partners, (Robot-machining $\mathrm{GmbH}$, 3D-Schilling $\mathrm{GmbH}$, Robotized $\mathrm{GmbH}$ )

\section{REFERENCES}

[3M 2021] 3M United States; Products - Adhesives, Sealants \& Fillers, Online: www.3m.com, 2021.

[Arbesman 2000] Arbesman, R.; Brake plate and method and apparatus for manufacturing same; WO2000049308A1, 24.08.2000

[Brand 2016] Brand, M.; Kühn, M.; Müller, A.; Klaus, K.; Enhancing the tensile strength in hybrid Metal-FRPMaterials through various interlocking structure patterns In: EURO HYBRID - Materials and Structures 2016, Kaiserslautern, Germany, page 251, 2016
[Chen 2018] Chen, Y.H.; Dong, F.H.; Robot machining: recent development and future research issues. International Journal of Advanced Manufacturing Technology, 2013. 66 (9-12): p. 1489-1497

[Chen 2018a] Chen C.; Peng; F., Yan, R.; Fan, Z; Li, Y; Wie, D:; Posture-dependent stability prediction of a milling industrial robot based on inverse distance weighted method; in 28th International Conference on Flexible Automation and Intelligent Manufacturing (FAIM2018), June 11-14, 2018, Columbus, OH, USA; Procedia Manufacturing 17 (2018) 993-100]

[Dross 2021] Dross, M.; Albergt, M.; David, M.; Reichler, A.K.; Hoffmeister, H.-W.; Dröder, K.; Combined robot-based manufacturing and machining of multi-material components; Int. J. Adv. Manuf. Technol. (2021). https://doi.org/10.1007/s00170-021-07008-3

[Gradinger 2010] Gradinger, R.; Ucsnik, S.; FEM-basierte Untersuchungen einer innovativen Metall-FVK Fuegetechnik. AIT Austrian Institut of Technologie. LKR Leicht-metallkompetenzzentrum Ranshofen $\mathrm{GmbH}$. Hybridica Forum, 2010

[Klimchik 2016] Pan, Z; Zhang, H; Zhu, Z; Wang, J; Chatter analysis of robotic machining process. Journal of Materials Processing Technology, 173 (2006)301-309.]

[Lejun 2017] Lejun, C; Melkote, S. N.; „Effect of Robot Dynamica on the Milling Forces in Robotic Milling; in 5th SME North American Manufacturing Research Conference, NAMRC 45, LA, USA; Procedia Manufacturing 10 (2017) $486-496$

[Maidin 2015] Maidin, S.; Jaafar, M. H.; „Design and Manufacture of Recurve Bow Riser Using Fused Deposition Modelling and Fibre-Reinforced Composite Material"; In: Applied Mechanics and Materials, Vol. 786, Chapter 4: Applied Mechanics, Design and Manufacturing, S. 300-304, 08/2015

[Mejri 2016] Mejri, S., et al., Dynamic characterization of machining robot and stability analysis. International Journal of Advanced Manufacturing Technology, 2016. 82(1-4): $p$. 351-359

[Pan 2006] Pan, Z., et al., Chatter analysis of robotic machining process. Journal of Materials Processing Technology, 2006. 173(3): p. 301-309.

[Rauch 2009] Rauch, M.; „Pinnen“, was nicht zu schweißen ist Metall mit organischem Material verpinnen. Pressemitteilung Fronius International $\mathrm{GmbH}, 2009$

[Reichler 2019] Dröder, K; Reichler, A; Mahlfeld, G.; Droß, M.; Gerbers, R.; Scalable Process Chain for Flexible Production of Metal-Plastic Lightweight Structures, 2nd CIRP Conference on Composite Material Parts Manufacturing (CIRP-CCMPM 2019), Procedia CIRP 85 (2019 195-200)

[Witten 2018] Witten E, Mathes V, Sauer M, Kuehnel M. Composites market report 2018: market developments, trends, outlooks and challenges. availabel online: https://www.avk-tv.de/infothek.php 